\title{
The experiences of pregnant migrant women in detention; a qualitative study
}

\begin{abstract}
Pregnant migrant women held in detention centres in the UK can be particularly vulnerable. They may have poor physical and mental health, exacerbated by their incarceration. They are at a disproportionally increased risk of maternal and perinatal mortality. Unpublished studies have found that pregnant migrant women have poor experiences in detention.

This article describes a phenomenological study aiming to explore pregnant migrant women's experiences of living in detention. Four migrant women who had been held in detention whilst pregnant and two volunteer health professionals were interviewed. Findings suggest that migrant women have very poor experiences in detention. Four key themes emerged 'challenges to accessing UK health care', 'exacerbation of mental health conditions, 'feeling hungry' and 'lack of privacy'. These findings could be used to review maternity care in detention and ensure detention staff understand the experiences of detained pregnant women so the needs of this vulnerable group can be met.
\end{abstract}

\section{Background}

Pregnant migrant women can be held in detention in the UK for a number of reasons. These include on arrival whilst awaiting a decision on their right to entry, they may have been refused permission to stay and are awaiting removal. They can be detained if they are considered not to have the right of residency, having an expired or no visa or have been refused asylum. In reality, pregnant migrant women are a vulnerable group, who may have fled their home for fear of persecution, having witnessed violence and lost family members. 
They may have been the victims of rape, torture, trafficking, forced marriage and sex working (Tsangarides and Grant, 2013, Public Health England, 2017)..

Prior to 2016, around 100 migrant pregnant women were held each year in detention often for prolonged periods (Tsangarides and Grant, 2013). Since then, following a Home office review, numbers have reduced. Women can only be detained when necessary, for up to 72 hours, but exceptionally for a week. However, it is argued that women are still being detained unnecessarily (International Detention Coalition, 2016) and that detention is harmful to their health (Tsangarides and Grant, 2013). Less than $20 \%$ of pregnant women who are detained are subsequently deported, questioning its value in controlling immigration (Shaw, 2016)

Half of detained migrants have claimed asylum at some point in their immigration journey (The Migration Observatory, 2017) and pregnant asylum seeking women are much more likely to have poor underlying physical and mental health leading to complex pregnancies and a proportionally higher risk of maternal and perinatal complications (Yelland et al., 2015, Asif et al., 2015, CMACE, 2011). A case series review found that pregnant migrant women in detention were seven times more likely to have a high risk pregnancy than the average UK woman (Pallotti and Forbes, 2016). The latest MBRRACE report found that non UK born women made up a quarter of maternal deaths in the UK and $12 \%$ of these women were refugees (Knight et al., 2016). Stress associated with migration is believed to contribute to the poor health of pregnant women increasing blood pressure, anxiety and depression (Brunner and Marmot, 2006). Anecdotal evidence suggests that poor conditions in detention centres can further exacerbate women's poor mental and physical health, even for short stay (International Detention Coalition, 2016)

Pregnant asylum seeking women are included in the NICE (2010) guidelines to improve maternity services for women with complex social factors. When considering their vulnerability in detention, it is argued that it is essential that 
they receive good quality maternity care to maintain their physical and mental health. An unpublished study by Medical Justice Charity (Tsangarides and Grant, 2013) found migrant pregnant women held in detention live in poor conditions and receive inadequate health care. However, a systematic literature review found little published primary research to support this. Two studies eluded to pregnant migrant women experiencing difficulties accessing health care in a detention centre (Lephard and Haith-Cooper, 2016, Feldman, 2014) but there is a lack of published research exploring this issue in more depth. Consequently, the aim of this study was to explore pregnant migrant women's experiences of living in detention, in order to understand maternity care provision and the impact of detention on pregnant migrant women's' health.

\section{Methodology}

A hermeneutic phenomenological approach was adopted (Todres and Holloway, 2011) to understand migrant women's perceptions of their lived experiences of being detained whilst pregnant.

Following ethical approval, participants were identified by cascading a request through voluntary sector networks. In addition, snowball sampling occurred through friends and peers. Participants were purposefully selected having had the experience of being held in detention for part of their pregnancy (see table 1 for inclusion criteria). There was no budget available for interpreters but all women had good spoken English language skills. Due to difficulties recruiting the minimum sample size of six considered appropriate for this type of study (Todres and Holloway, 2011), the same sampling approach was adopted to recruit two health professionals with the lived experience of working in a voluntary capacity with pregnant migrant women who had been detained.

In depth interviews were undertaken with four migrant women and two volunteering health professionals. The interview commenced with an open question facilitating the participants to talk through their experiences. Prompts 
were developed to guide the direction of the conversation and encourage a more in depth exploration of specific issues that were raised (see table 2). Each interview lasted around an hour. Interviews were conducted in a neutral, confidential environment, were audio recorded and transcribed verbatim.

Data were thematically analysed utilising Braun and Clarke (2006) six stages. This involved immersing in the data by reading and re-reading the transcripts, coding the data then grouping the codes into themes. Theme names and clear working definitions were developed. To reduce the risk of bias the codes and themes were compared to the original data by the researcher's academic supervisor.

Ethical approval was obtained from the local University Ethics Panel on the 10/05/17, reference E599. Women and volunteers who expressed an interest in the study had their contact details taken and were referred on to the researcher. A detailed explanation of the study was provided by phone, using the information sheet as a guide. A minimum of 24 hours was provided before contact was made again and a location arranged to undertake the interview. This began with a check through the information sheet and consent form and informed consent was gained. This was written consent for the volunteers. However, verbal consent was obtained from the women due to the possible fear that providing a signature could affect their immigration status. The women were asked to confirm into the audio recorder that they understood the information sheet and consent form.

Assurances of confidentiality and anonymity were important for this study and it was made particularly clear that these would be respected unless a concern arose around the safety of the woman or her child. In this case, a referral would be made, most likely through the voluntary sector. Women were reassured that the researcher had no links with the Home Office and the data would only be used for research purposes. Participants were informed that should they change their mind, they would be able to withdraw their consent up until the 
writing of the final report. There was the potential that participants may recall upsetting experiences due to the nature of the topic area. They were offered the opportunity to debrief following the interview and if required, be signposted to psychological support services. Anonymity was maintained by removing names of study participants and organisations and allocating numbers to the women. Transcripts were stored in a password-protected computer file and locked filing box accessible only to the researcher and her academic supervisor, and once transcribed by the researcher, audio-recordings were destroyed.

\section{Findings}

Two women were from Eastern Europe, one Sub-Saharan Africa and one from India. They were all experiencing their first pregnancy when held in detention for between 53-212 days. They were currently living in different towns and cities across the North of England, Midlands and London. The two volunteers were trained midwives who were experienced volunteers in a detention centre. Four key themes emerged from the data 'challenges in accessing maternity care', 'Exacerbation of mental health conditions', 'feeling hungry' and 'lack of privacy'. The verbatim is coded P1-4 for the women and HP1-2 for the volunteer health professionals.

\section{Challenges in accessing maternity care}

All the women and volunteers recalled times when antenatal care had been disrupted due to a lack of available midwives in the detention centre. Midwives provided appointments but there were not enough available for the demand. Consequently the volunteers stressed appropriately timed care was not undertaken. There was a lack of continuity of care, women seeing a different midwife at every appointment which the women found frustrating. In addition, midwives were not available in between appointments should the women have any concerns: 
'I would like to see the midwife because I would like to know what's happening... just want to hear my baby heart beat...so I would wait all day but the midwife never come back to see me' (P3)

Due to a lack of security staff to escort women to external appointments in the NHS, they were frequently cancelled:

'I remember very well I had to for a scan... and they said no we don't have the security, we don't have so many people that can go with you' (P4)

Women described situations where they felt unwell and were not believed by the staff. One woman described how she felt ill and was made to wait for hours for an appointment:

'I was feeling sore throat and high temperature...I had bad experience with urinary tract infections...I used to be trafficked woman...I told officer please can I see doctor, he told me doctor will come later...I feel like l'm dying I couldn't walk...I feel like they didn't care for me...I feel like they treated me like dog' (P2) (P2) was subsequently hospitalised with pyelonephritis.

(HP1) recalled a time when a woman with a history of ectopic pregnancy experienced vaginal bleeding. Her symptoms were not followed up by a nurse, despite seeing her sanitary pad:

'..She did rupture, she didn't die bit it was close thing' HP1

\section{Exacerbation of mental health conditions}

All the women had a previously diagnosed mental health condition which they felt was exacerbated due to the circumstances in which they were living in detention.

'I was depressed, I was stressed... just being isolated, no privacy, men walking in...feeling powerless' (P2) 
The volunteers stressed that detention staff did not recognise that mental health could deteriorate in detention and in pregnancy and women were not listened to when they expressed concerns about their deteriorating mental health:

'When it came to mental health, it's only about what someone says, there's little physical to see so the women were always completely dismissed' (HP1)

There also appeared to be situations where women were not given appropriate medication. One woman described how in detention, she didn't receive her prescribed regular medication which negatively impacted on her mental health:

'I feel suicidal...I was scared for my baby...what's going to happen next...' (P4) In addition, appropriate referrals did not appear to be made for women who required support with their mental health:

'I had a history of depression and you tell them...they are like oh yes we will get in touch with a doctor...but they never do' (P1).

\section{Feeling hungry}

All participants discussed the provision of food in detention. They all felt that food was poor quality, unpalatable and was not a balanced diet. Not enough food was provided and there was inflexibility in the timing of meals. Participants described how women were offered food not suitable for pregnant women:

'The food was appalling like it was basically just chips. They were supposed to provide a balanced diet but they didn't' (HP2)

'The food was too spicy... I didn't like the food. I was vomiting all the time and just eating to keep surviving for my baby' (P2)

One woman raised these issues with the staff but was ignored. All the women felt hungry in between meals, especially in the evenings and were not allowed to take any food back to their room to snack. They therefore remained hungry. 
'I requested the manager to keep some food in my room because I get hungry at night...but they refuse...I was so upset... It is just food we are asking for nothing else' (P4)

Another woman described how she would conceal food such as biscuits in her room to eat during the night when she felt hungry.

\section{Lack of privacy}

All participants discussed a lack of privacy in detention centres. Male and female officers would enter women's room to perform random checks without any warning. This included when women were having a shower or visiting the toilet:

'When I go to the toilet I feel scared there because the guards they can just come in at any time...I feel they can come in when I am changing...so I write a note and put it on the door and the male officer took and said I can't put anything like that' (P4)

The women described situations where there was a lack of privacy when they were taken for appointments in the NHS:

'When the scan was going on the officer was also in...I kind of felt upset... (P3)

'We went to the labour ward ...the midwife ask the guards to leave because she need to check me...the guard ask her to leave the door open because we need to know what's happening' (P2)

There was also a concern about a lack of privacy when receiving care from health professionals in the detention centre. (HP1) recalled an experience when a woman requested to be examined due to previous female genital mutilation. The clinic doors would not lock and she received five interruptions whilst trying to undertake the procedure. 


\section{Discussion}

This study confirms that pregnant migrant women held in detention are subjected to conditions which can impact on their physical and mental health and potentially that of their baby, supporting previous unpublished work (Tsangarides and Grant, 2013). In this study women struggled to access timely and appropriate maternity care, instead receiving basic ad hoc care and were ignored when they alerted staff to their health concerns. There was no continuity of care provided and NICE antenatal care guidelines for timing of appointments were not followed (NICE, 2017). External appointments were frequently cancelled due to a lack of guards to escort the women.

Most women stated they suffered from pre-existing mental health conditions exacerbated by being in detention. These were ignored and current medication was withheld. The CMACE (2011) report specifically focuses on deteriorating mental health in pregnancy recommending counselling and support services. In addition, there is a growing body of evidence for example (Glover et al., 2010, Capron et al., 2015) that children of mothers who are exposed to stress in the antenatal period are more likely to develop childhood and emotional behavioural difficulties, therefore it is paramount that women are able to access mental health services.

It was anticipated through the prompts, that women would discuss their experiences of pregnancy and compare their care to the maternity care they subsequently received out of detention. However, in reality, the living conditions that women experienced were at the forefront of their minds and feeling hungry was discussed by all of the women. There is a growing body of evidence that a mother's diet can influence fetal development for example (Englund-Ogge et al., 
2014, Borge et al., 2017). It is vital therefore that migrant woman in detention have access to a healthy balanced diet to benefit their health and also their babies.

\section{Implications of findings}

This study commenced prior to the 2016 Home Office review when length of detention was reduced to a maximum of 72 hours. Women in this study were detained for between 53-212 days. Consequently, one could question the relevance of the findings. The small sample size of this study could also be questionable. However, it is argued that even short periods in detention can have a negative impact on mental and physical health (International Detention Coalition, 2016). Whilst in detention, if a woman's health does deteriorate then it is essential that knowledgeable staff act on this is in a timely manner to ensure potentially life threatening obstetric emergencies are avoided.

Health professionals and officers need to undertake training to ensure they understand the health needs of pregnant migrant women and how to manage deterioration in health, ensuring immediate access to health care services as required. However they also need to understand the importance of flexibility around food and appropriate foods that should be provided. There needs to be a better understanding of privacy in detention, ensuring a woman centred approach and good communication skills.

All of the women in this study continue to live in the UK following detention rather than being deported. Consequently, this demonstrates the importance of providing good quality, uninterrupted maternity care whilst pregnant women are in detention that can be followed up when they are released back into the community. There has been a drive for improved maternity care in prisons in the UK for example through the birth companions initiative (Marshall, 2010) where NHS providers undertake regular antenatal care that continues once women leave prison. A similar concept in immigration detention centres could ensure 
that migrant women receive the same level of care but also that this prepares them for community midwifery on leaving the detention centre.

\section{Conclusion}

Pregnant migrant women held in detention are a vulnerable group with poor underlying mental and physical health exacerbated by the detention process. Vulnerable migrant women have some of the poorest maternal and perinatal outcomes compared to other women. It is essential that midwives who subsequently care for women who have been held in detention have an awareness of the experiences that women may have encountered to ensure their physical and mental health is monitored through the remainder of their maternity journey.

Although this is a small study, the participants were currently living in different locations across the UK and the themes developed were generic, reflecting all participants' lived experiences. They also add to the current small body of evidence around pregnant migrants women experiences in detention. It is recommended that maternity care in detention is reviewed and the evidence from care of pregnant women in prisons used to develop services.

\section{$\underline{\text { Key Phrases }}$}

- Pregnant migrant women in detention are a vulnerable group with complex health needs resulting in a higher rate of maternal and perinatal mortality

- Women in detention experienced disrupted maternity and mental health care

- Findings from this study support unpublished previous research that this client group continues to struggle to access the care they need

- Staff working in detention centres need training around the complex health needs of this group as recommended by the NICE guidelines. 
Table 1 Study inclusion criteria

- Women aged over 18

- Experienced some/all of their pregnancy in detention

- Had a healthy baby in the last 2 years

- Adequate English language skills or can bring someone who can translate for them

- Will not have been involved in a similar study in the last 2 years

Table 2 Prompts used during interviews

- Accommodation and food

- Health/parent Education

- Experience of different stages of pregnancy

- Health care provided including antenatal care

Women only: Health care after leaving detention and comparison with care in detention 


\section{References}

ASIF, S., BAUGH, A. \& WYN JONES, N. 2015. The obstetric care of asylum seekers and refugee women in the UK. The Obstetrician \& Gynaecologist, 17, 223-231.

BORGE, T., AASE, H., BRANTSÆTER, A. \& BIELE, G. 2017. The importance of maternal diet quality during pregnancy on cognitive and behavioural outcomes in children: a systematic review and meta-analysis. British Medical Journal, 7, e016777.

BRAUN, V. \& CLARKE, V. 2006. Using thematic analysis in psychology. Qualitative Research in Psychology, 3, 77-101.

BRUNNER, E. \& MARMOT, M. 2006. Social Organization, Stress and Health. In: MARMOT, M. \& WILKINSON, R. (eds.) Social Determinants of Health. 2nd ed. Oxford: Oxford University Press.

CAPRON, L., GLOVER, V. \& RAMCHANDANI, P. 2015. Does maternal antenatal depression alter infant hypothalamic-pituitary-adrenal (HPA) axis functioning in the offspring at 4 months postpartum? .

Psychoneuroendocrinology, 61, 33.

CMACE 2011. Saving Mothers' Lives: reviewing maternal deaths to make motherhood safer: 2006-08. The Eighth Report on Confidential Enquiries into Maternal Deaths in the United Kingdom. London: CMACE.

ENGLUND-OGGE, L., BRANTSAETER, A., SENGPIEL, V., HAUGEN, M., BIRGISDOTTIR, B., MYHRE, R., MELTZER, H. \& JACOBSSON, B. 2014. Maternal dietary patterns and preterm delivery: results from large prospective cohort study. British Medical Journal, 348, 1446.

FELDMAN, R. 2014. When maternity doesn't matter: Dispersing pregnant women seeking asylum. British Journal of Midwifery, 22, 22-28.

GLOVER, V., O'CONNOR, T. \& O'DONNELL, K. 2010. Prenatal stress and the programming of the HPA axis. Neuroscience \& Biobehavioral Reviews, 35, 17-22.

INTERNATIONAL DETENTION COALITION. 2016. What is immigration detention? [Online]. Available: https://idcoalition.org/aboutus/what-isdetention/\#1496020646137-3f15ff68-6f48 [Accessed 19th February 2018].

KNIGHT, M., NAIR, M., TUFFNELL, D., KENYON, S., SHAKESPEARE, J., BROCKLEHURST, P. \& KURINCZU, K. J. 2016. Saving Lives, Improving Mothers' Care - Surveillance of maternal deaths in the UK 2012-14 and lessons learned to inform maternity care from the UK and Ireland Confidential Enquiries into Maternal Deaths and Morbidity 2009-14. MBRRACE-UK. University of Oxford: National Perinatal Epidemiology Unit.

LEPHARD, E. \& HAITH-COOPER, M. 2016. Pregnant and seeking asylum; exploring experiences 'from booking to baby'. British Journal of Midwifery, 24, 130-136.

MARSHALL, D. 2010. Birth companions: working with women in prison giving birth. British Journal of Midwifery, 8, 225-228. 
NICE 2010. Pregnancy and complex social factors. A model for service provision for pregnant women with complex social factors. London: National Institute for Health and Clinical Excellence.

NICE 2017. Antenatal care for uncomplicated pregnancies. London: National Institute for Health and Clinical Excellence.

PALLOTTI, P. \& FORBES, M. 2016. Mothers in immigration detention. The most vulnerable and the hardest to reach. A case series review. Practicing Midwife, 19.

PUBLIC HEALTH ENGLAND 2017. Vulnerable Migrants: Migrant Health Guide.

SHAW, S. 2016. Review into the welfare in detention of vulnerable persons. London: Home Office.

THE MIGRATION OBSERVATORY. 2017. Immigration detention in the UK [Online]. Oxford: University of Oxford. Available:

http://www.migrationobservatory.ox.ac.uk/resources/briefings/immigratio n-detention-in-the-uk [Accessed 20th February 2018].

TODRES, L. \& HOLLOWAY, I. 2011. Phenomenological Research. In: K, G. \& LACEY, A. (eds.) The Research Process in Nursing. 6th ed. Chichester: Wiley-Blackwell.

TSANGARIDES, N. \& GRANT, J. 2013. Expecting change: The case for ending the detention of pregnant women. London: Medical Justice.

YELLAND, J., RIGGS, E., SZWARC, J., CASEY, S., DAWSON, W., VANPRAAG, D., EAST, C., WALLACE, E., TEALE, G., HARRISON, B., PETSCHEL, P., FURLER, J., GOLDFELD, S., MENSAH, F., BIRO, M., WILLEY, S., CHENG, I., SMALL, R. \& BROWN, S. 2015. Bridging the Gap: using an interrupted time series design to evaluate systems reform addressing refugee maternal and child health inequalities.

Implementation Science, 10. 